\title{
Contemporary Issues in Teaching and Learning with Technology
}

\author{
Dr. Jerry P. Galloway
}

\section{INTRODUCTION}

To speak of contemporary issues in instructional technology is like counting wave crests in a stormy ocean; they are changing quickly all the time. New technologies and new issues present themselves daily. Educators struggle with both the instructional integration of computing and developing the skills and knowledge necessary to use technology effectively (Lipscomb \& Doppen, 2005). Why, after over 30 years of having computers in schools, are educators still having such difficulties?

Today's population is much more accustom to electronics yet knowledge is weak, concepts are misunderstood and the difficulties of teaching with technology seem as serious and convoluted today as ever before. The great physicist and thinker, Richard Feynman, offered some critical comments about the challenges of educators. "What happens is that you get all kinds of statements of fact about education, about sociology, even psychology - all kinds of things which are, l'd say, pseudoscience" (Feynman, 1999, p. 242). Today, we understand "more about education... [but] the test scores are going down...we just don't understand it at all. It just isn't working." (p. 243). Being critical of how the scientific method is applied to education, Dr. Feynman's comments highlight how the study of teaching and learning yields limited or questionable results. Teacher trainers take their best guess on how to prepare teachers to use technology.

\section{BACKGROUND}

Educational computing is a relatively new discipline compared to mathematics and science. While the earliest uses of computers might have been by departments of mathematics, it quickly became important for virtually all teachers to become computer literate. But, what exactly that entails was not exactly clear (Galloway, 1985) for learning and in society (Beaty \& Tucker, 1987).

Microcomputer technology, primitive by today's standards, lacked user-friendly applications, any sort of consistent user-interface, or easy-to-use telecommunications and interconnectivity. There was an early division between those who learned to program computers versus those who focused more exclusively on applications software. Conceptual development, improvement of problem-solving and higher-order thinking skills in computing have been directly linked to the inclusion of Logo programming (Allen, 1993; Battista, 1994; Borer, 1993; Dalton \& Goodrum, 1991) and BASIC programming (Overbaugh, 1993). Yet, in 
spite of an overwhelming need to operate early microcomputers through programming, educators focused instead on the actions and procedural tasks of specific applications (Galloway \& Bright, 1987).

With this as a foundation, decades of training have followed in which educators have tried to master new devices and software. So, how long does it take to reach a point of nationwide competency, to develop the protocols of effective use, to establish the knowledge of how best to learn computing? Compared to centuries of science and mathematics, perhaps our 30plus years don't seem so long.

\section{EDUCATORS LEARN COMPUTING: A PROBLEM OF PERSPECTIVE}

Our collective perspective on what it means to learn computing affect what goals we pursue and how we proceed. For example, the use of rubrics or portfolios were not commonly emphasized in education 30 years ago. Today, they are an accepted or at least popular tool for preparing educators (Galloway, 2006; The Rural School and Community Trust, 2001). Does this represent progress or perhaps just a symptom of changing fads? Is this a function of real knowledge or mere opinions? This is again reminiscent of a Feynman criticism (Feynman, 1999) as he suggests that professionals 30 years ago have as much right to a correct opinion as we have today, "to equally unscientifically come to a conclusion" (p. 243) - even if wrong.

\section{Preparing Teachers}

It is unlikely that educators younger than their mid-40's graduated high school without having computers in their education. There has been, since the late 1970's, a continual focus on the needs of teachers to learn and adapt to a technology-based profession.

Our attempt over the years to change educators into computer literate professionals essentially failed. Many will argue the point as clearly there are countless success stories. But, with the exception of the techies and innovative pioneers, educators across the profession a generation ago did not, have not changed their basic approach to integrate technology.

Compared to in-service classes, college courses, training or other options, an overwhelming majority of teachers maintain that their primary methods of learning computing was through self-study and personal experimentation (Galloway, 1997). It can be argued that teachers must assume a responsibility for advancing their technological knowledge and be engaged learners.

When taking a computer class, one must go beyond the prescribed activities. For example, it is not likely that one would be assigned the experience of losing a file or to open a file with the wrong program. These frustrations can be a very necessary part of learning. Far too often educators are passive and restrict their involvement to occasional and discrete enrichment offered through someone else's initiative. Delays, intermittent and partial commitments inhibit learning.

As an analogy, when this author was young, rock-n-roll music was still the choice of the young, but grandfather did not relate and found it quite distasteful. In elevators, in 1968, one would hear music from Lawrence Welk and such. This author believed that if elders could simply understand and learn about rock-n-roll and what the artists were attempting to musically express that society could change and the music would be accepted. Today, one is 
likely to hear McCartney, Dillon, The Beatles, Buddy Holly or many of the other artists that were objectionable in those earlier years. One might think that, indeed, things changed.

However, the point is that this did not occur because the elders were influenced or convinced. The younger, rock-n-roll generation did not change anyone. The elders were not convinced. No metamorphosis occurred. The young simply grew older and brought their music with them. As the elders died off, the young with a new culture replaced the old.

The same seems true for the computer-using generation. Our efforts a generation ago were ineffective. We have simply waited around while a new generation grows older bringing their technology-based lifestyle with them. Until our children have time to take their place, today's teachers are still introduced to computing as beginners.

\section{Training vs. Education}

What do current educators expect from computer training? If we accept that it is difficult to teach someone who doesn't want to learn, what do students expect from their training? Unfortunately, the most popular notion in instructional technology is that teachers are to be trained, not educated. More than mere semantics, teaching tends to emphasize showing teachers how to use technology - rather than facilitating insight, understanding, and conceptual development. In-service programs and college curricula emphasize only what teachers are expected to use rather than what might develop good concepts. Omitting programming is a classic example where teachers as end-users of software never see the construction process or design methods behind what they are supposed to learn. Today's design tools (for web pages and such) are modern example where these issues still apply.

Teaching for conceptual understanding and higher-order thinking skills should not be only a part of teaching programming (Tu \& Falgout, 1995) but also a fundamental goal of instruction for beginners in computing. Skills and even performance standards can still fail to generate important understandings, perspectives, concepts - integrated knowledge - that all contribute a fundamental and critical basis for problem-solving and adaptability.

Focusing on conceptual development will still involve procedures and tasks just as focusing on discrete skills will likely yield some insights and discoveries. But, instruction should yield a more complete, fundamental understanding of computing. Most programs and perspectives fail to recognize this important viewpoint and instead pursue skills and competencies to the detriment of understanding, insight and problem solving.

It is common in other disciplines to speak of education rather than training. Conceptual development is often the primary focus in the study of science (Trumper, 1997). Even when the preparation of teachers is described in terms of training, science concepts are emphasized, not skills (Thompson \& Schumacher, 1995). In spite of the procedures and skills inherent in science and mathematics, students are guided toward the development of a conceptual understanding as they are educated - not trained.

A training model targets activities and the software teachers will use. Much like an airline reservations clerk must learn the keystrokes and procedures for prescribed tasks, educational computing is similarly conceived. An education model, on the other hand, calls for activities and experiences that will yield a deeper kind of learning. Keystrokes and software familiarity would be incidental to the more important yield of experiences, much like those in science and mathematics, that develop understanding, concepts, problem solving and critical 
thinking skills. An education-based program would provide experiences because of their educational value regardless of whether they are part of an anticipated skill set. Skill sets, tasks and the procedural rituals of training will inevitably change and evolve far beyond the scope of any training experience.

Student teachers can be part of the problem as they, very often, prefer the training model. Contrary to any real value or longevity of such an approach, a more involved education presents an undesirable challenge. They prefer to simply be shown what to do. Guided tasks, prescribed procedures, discrete tasks are all a matter of doing, not becoming. However, an education calls for change.

Acquiring mindless task sequences is often viewed by educators as success. Improved teaching is then viewed as having more complete check lists for more tasks. This recipe mentality of discrete procedural rituals ignores the need for discovery learning, transfer and adaptability and could be responsible for continuing the inhibited progress of the past 30 years.

\section{Integration}

Limiting factors for the integration of technology include funding, professional development, support for experimentation, and inadequate technology planning (Mehlinger \& Powers, 2002). As Galloway (1997) examined technology adoption it was learned that effective usage is related to the combination of both professional and personal adoption of technology. Virtually no one used technology in their classrooms where personal adoption was not combined with professional use.

It has been said that teachers exist only for the children. They express the sentiment that student needs are the primary if not the only mission of teachers. It is easy, however, to draw the wrong conclusions from such a self-evident premise. For instructional technology, consistent with this perspective, trends have been directed away from empowering teachers focusing instead on classroom integration. This may seem justified but a serious problem remains: it is not reasonable to teach non-computer-users to use technology in the classroom. Educating teachers to become computer-using, technology-competent professionals would more likely yield classroom integration as a matter of natural consequence.

While there are training programs targeting classroom integration, what success can be had if teachers are not computer-literate or have never adopted computing in their lives? In other words, one must adopt technology as a life-changing metamorphosis. The approach of the past, training over education and rituals over holistic, adoption may likely continue the inhibited progress in integration and technological mastery.

\section{Learning and Working}

Everyone agrees that students must be prepared for a technological future but perceptions vary widely on exactly how to achieve that. This is a challenge of pedagogy.

Computers have been perceived as tools (Beaty \& Tucker, 1987) and have been used in that fashion. An alternative view might suggest that the computer is not a tool at all. As a tool might be selected or discarded based on a particular need, technology is too often viewed as independent from everyday life powered-up if the need is sufficiently demanding. Instead, computers are perhaps best viewed as a complete environment. It is where we live, work and play. It is the medium of our planning, our creativity and an extension of both our short-term 
and long-term memory. This thinking places different expectations on educators than has traditionally been made. The notion that one can remain a non-computer-using person while merely executing discrete tasks as needed must change.

\section{FUTURE TRENDS}

How has learning changed and what is learning in the modern tech-based world? Learning is far too often viewed by teachers as a matter of acquiring information. Teachers deliver information to the students who in turn sit on it for a period of time only to hand it back to teachers again in some form of quiz or standardized test. If students regurgitate and return the information accurately they are said to have learned. In fact, students assume this is what is expected of them and resist anything more personally demanding. The notion that they must change, must invent or synthesize is foreign to them.

Learning is no longer about the acquisition of information. We have information. It is possible to find the average price of a hang guilder, the architect of the Brooklyn Bridge, design plans for a new home or a translation of the Dead Sea Scrolls in mere minutes - all while sitting in a hotel lobby or even lying in bed in a dormitory room. Acquisition to information is neither the problem nor the goal. Learning to think is the real challenge. Education has become about skill development with demonstrable competencies rather than about becoming smarter or learning to think. Education, as distinct from training, should improve problem solving abilities, critical thinking abilities, developing an understanding, learning to discriminate and make good choices, and the development of a contextual intuition.

Computing students do not want to have to explore and discover, wanting, instead to be shown how to execute procedures. Alluded to earlier, this amounts to distributing recipes for subsequent replication. Being ready for tomorrow's computing world depends on understanding, problem solving skills and the ability to adapt to the unknown - not on knowing procedures in some software program.

Technology continues to develop faster than anyone can sufficiently learn it. Merely being able to operate the functions and tools in a program is usually considered a success. But, achieving a deeper knowledge of how best to adopt, integrate and teach in a world of technology is quite a different thing.

\section{The Distant Future}

Does today's science fantasy help to create the reality of tomorrow? That is of course debatable but at least imagination does its part on one side of the evolution equation. Clearly, our children will experience amazing and incredible advancements that today seem like science fiction.

So, extend your vision to consider the following: a kind of futuristic electronic bubble as a kind of spherical energy shell that would surround one's head and face. The shell might not be spherical and could instead extend vertically downward in front of the face and chest somewhat like a large energy shield in front of the body. Generally, it may be maintained and kept active throughout the waking hours.

The shell or E-Bubble would be generated by a multifunctional microchip and would act like a virtual outer skin or electronic membrane extending perhaps 10 to 12 inches in front of 
the body. Perhaps the orientation of the membrane (up/down, sections, areas, etc.) could be determined by detecting and interfacing with an electrical field from the heart or brain much like an electrocardiogram or electroencephalogram. This would be important to establish a directional configuration since a microchip might be located more on convenience or medical necessity. The E-Bubble should maintain a functional orientation to the body. The membrane can function in sections, quadrants or areas as well as operating as a whole or singular entity.

The E-Bubble would serve as a communications interface for all sorts of input and output in work, learning and recreation. The microchip and power supply might be worn as external hardware, like in a necklace, belt buckle or collar. Perhaps the electronic membrane might exist in the form of a mere hologram projection from specialized glasses. Today's military pilots see electronic projections of critical data superimposed on their natural view of their environment during flight. Some hardware today can feed visual information into one eye leaving the other eye normal as the brain integrates the two views. The integration of visual and auditory hardware with the body has already begun its prosthetic progression from the separate and independent technologies of yesterday's cathode-ray tube (CRT) and today's plasma flat screens.

Eventually, the development of the E-Bubble would evolve beyond the independent device carried in hand. Even with the convenience of a wrist watch or techno-necklace, such devices are external and, thus, their service to our lives is an add-on not truly integrated and natural. The E-Bubble will evolve beyond a separate prosthetic to such a size and state that it becomes an implant no more intrusive than an inner ear replacement.

Images displayed in the membrane fields, would include all of the variations we know of today: pictures, graphics, text, color, and of course, full-motion video. One can imagine that these fields appear from the back side, viewed by others, as opaque with no detail or instead translucent with imagery appearing in reverse.

One can imagine interactive fields for drawing, writing or other tactile manipulations. Perhaps an image might be relocated in the field matrix to open or power another area for a secondary purpose. The various fields might provide a multi-tasking experience of work and play, business and entertainment, or integrated learning and study experiences.

It is really an extension of what has already occurred. Star Trek and many other sources of imagination today illustrate not just an exciting possibility but an inevitable reality.

\section{CONCLUSION}

Are we to continue passively as followers of our children or step up as leaders, which the nobility of our profession demands? The overwhelming theme of the past 30 years is that training for discrete tasks must be replaced by holistic adoption and education. Being successful at computing is not a function of memorized procedures or specific skill sets. Procedural rituals, however conveniently arranged or exhaustively accounted, cannot substitute for intuition, problem solving and a deeper understanding of computing.

The future depends on adaptability and learning transfer which again attests to the inadequacy of mere training. It will be an exciting future but challenging to us all. To quote Peter Drucker, a $20^{\text {th }}$ century business pioneer, "The best way to predict the future is to create it." 


\section{REFERENCES}

Allen, J. (1993). The impact of cognitive styles on the problem-solving strategies used by preschool minority children in Logo microworlds. Journal of Computing in Childhood Education, 4 (3-4), 205-217.

Battista, M. T. (1994). Research into practice: Calculators and computers: Tools for mathematical exploration and empowerment. Arithmetic Teacher, 41 (7), 412-417.

Beaty, J. J., \& Tucker, W. H. (1987). The computer as a paintbrush. Columbus, OH: Merrill Publishing Co.

Borer, M., (1993). Integrating mandated Logo computer instruction into the second grade curriculum. M.S. Practicum Report, Nova University (ERIC Document No ED367311).

Dalton, D. W., Goodrum, D. A., (1991). The effects of computer programming on problemsolving skills and attitudes. Journal of Educational Computing Research, 7 (4), 483-506.

Feynman, R. P. (1999). Richard Feynman builds a universe. In J. Robbins (Ed.), The pleasure of finding things out: The best short works of Richard P. Feynman. (pp. 225-243). New York: Basic Books.

Galloway, J. P. (1985). What is computer literacy? Presentation at the Texas Computer Education Association Area IV Fall Conference, Houston, TX

Galloway, J. P., \& Bright, G. W. (1987). Erroneous conceptions of computing concepts. In J. D. Novak (Ed.), Proceedings of The Second International Seminar: Misconceptions and Educational Strategies in Science and Mathematics, Volume 1, (pp. 206-219). Ithaca, NY: Cornell University.

Galloway, J. P. (1997). How Teachers Use and Learn To Use Computers. Technology and Teacher Education Annual Journal, 1997. Published by the Association for the Advancement of Computing in Education, Charlottesville, VA.

Galloway, J. P. (2006). Electronic Portfolios for Educators. International Journal of Arts and Sciences, 1(1), 10-13.

Lipscomb, G. B., \& Doppen, F. H. (2005). Climbing the stairs: Pre-service social studies teachers' perceptions of technology integration. International Journal of Social Education, 19, 2.

Mehlinger, H. D., \& Powers, S. M. (2002). Technology and teacher education: A guide for educators and policymakers. Boston, Mass.: Houghton Mifflin.

Overbaugh, R. C., (1993). A BASIC programming curriculum for enhancing problem-solving ability. Evaluative Report, Darden College of Education, Old Dominion University, Norfolk, Virginia. (ERIC Document No ED355921).

The Rural School and Community Trust (2001). Assessing student work. Retrieved January 8 , 2007 from: http://www.ruraledu.org/site/c.beJMIZOCIrH/b.1389103/apps/s/content.asp?ct=83817 7

Thompson, G. W. \& Schumacher, L. G., (1995). Implications of integrating science in secondary agricultural education programs. Paper presented at the American Vocational Association Convention (Las Vegas, NV, December 1997). 
Trumper, R. (1997). The need for change in elementary school teacher training: The case of the energy concept as an example. Educational Research, 39 (2), 157-74.

Tu, Jho-Ju, \& Falgout, B. (1995). Teaching If-Then Structures: An Integrated Approach. Learning and Leading with Technology, 23 (3), 26-28.

\section{TERMS}
Educational Computing - Full range of uses of computers pursuant to conducting the profession.

Instructional Technology - The broader field of studying the use or related issues of all technologies in education.

Learning

Computer Literacy

Integration

Training

Education

Science Fiction
- Contrary to the acquisition of mere facts, and more than acquiring discrete skills and competencies, learning is the development of knowledge, conceptual understanding, and critical thinking abilities in a prescribed context.

- The ability to effectively use computer technology to solve problems and efficiently meet personal and professional needs

- The effective, instructional use of technology in the classroom.

- Limited and highly specific instruction for learning discrete tasks and procedural rituals.

- Contrary to mere training, the process engaging in supportive and generative experiences for acquiring the broader understanding and mastery.

- Imagining future developments in technology and the humanmachine interface including living and working in virtual worlds. 